\title{
Verdete de cedro do abaeté como fonte de potássio: caracterização, tratamento térmico e reação com $\mathrm{CaO}$
}

\author{
Verdete from cedro do abaeté as a source of potassium: \\ characterization, thermal treatment and reaction with $\mathrm{CaO}$
}

Silva, A. A. S. ${ }^{1}$; Medeiros, M. E ${ }^{1}$; Sampaio, J. A. ${ }^{2}$; Garrido, F. M. S. ${ }^{1}$

\author{
${ }^{1}$ Universidade Federal do Rio de Janeiro, Instituto de Química \\ Av. Athos da Silveira Ramos, 149 Bl A /7 andar, cep 21941-909, Cidade Universitária, Rio de Janeiro, RJ \\ e-mail: asoeiro@cetem.gov.br ; chico@iq.ufrj.br ; martam@iq.ufrj.br \\ ${ }^{2}$ Centro de Tecnologia Mineral, av. Pedro Calmon, 900 cep 21941-908, Cidade Universitária \\ Rio de Janeiro, RJ \\ e-mail: jsampaio@cetem.gov.br
}

\section{RESUMO}

O potássio é um dos principais macronutrientes presentes no solo. Entretanto, no Brasil este se torna escasso devido à elevada acidez dos solos tropicais. Dessa forma, a demanda por fontes alternativas de potássio cresce consideravelmente. Nesse contexto, foi realizada a caracterização química e mineralógica do verdete de Cedro do Abaeté, Minas Gerais, assim como, uma avaliação do tratamento térmico da mesma com ou sem a adição de $\mathrm{CaO}$, visando a solubilização do potássio presente na rocha.

A caracterização da rocha foi desenvolvida pelas técnicas de difração de raios X (DRX), fluorescência de raios X (FRX) e espectroscopia no infravermelho (IV). A avaliação dos resultados de FRX mostra que a rocha possui 6,95\% em massa de K2O, referente à presença de glauconita. Esta foi confirmada por DRX, devido à presença de picos característicos em 1,00; 0,45; 0,24 e 0,15 nm, e por IV pela ocorrência de bandas em 3520, 3440, 1020 e 630 cm-1. Há também alto teor de SiO2 (64,65\%), indicativo da presença de quartzo, que é caracterizado por um pico intenso em 0,335 nm.

Na etapa de tratamento térmico, o verdete foi aquecido por 2 horas a uma temperatura de $1200^{\circ} \mathrm{C}$. Para aumentar a solubilidade do potássio, presente na rocha, foi realizado a reação com óxido de cálcio nas proporções de 10, 20 e 30\%, em massa. As modificações estruturais na rocha foram acompanhadas por DRX e IV. Constatou-se reação entre a rocha e o óxido de cálcio, sendo observadas modificações na posição de bandas características do estiramento Si-O nos espectros de IV, em torno de $1100 \mathrm{~cm}-1$ e o desaparecimento dos picos de difração de raios X referentes à glauconita. A reação com $20 \%$ de $\mathrm{CaO}$ permitiu uma extração de 7,7\% do potássio presente na amostra.

Palavras-chave: Verdete, termopotássio, glauconita, fertilizante de liberação lenta.

\section{ABSTRACT}

The potassium is one of the most important macronutrients to the soil. However, in the Brazilian soils this nutrient becomes scarce due to the high acidity of tropical soils. Thus, the demand for alternative sources of potassium grows considerably. In this context, we performed a chemical and mineralogical characterization of a verdete from Cedro do Abaeté, Minas Gerais, as well as an evaluation of the verdete thermal treatment, with or without addition of calcium oxide $(\mathrm{CaO})$, in order to solubilize the potassium present in the rock.

The characterization of this rock was developed by the techniques of X-ray diffraction (XRD), X-ray fluorescence (XRF) and infrared spectroscopy (IR). The evaluation of the XRF results showed that the rock has 6,95 mass\% of K2O, related to the presence of glauconite. This was confirmed by the XRD due to the presence of characteristics peaks at 1.0, 0.45, 0.24 e $0.15 \mathrm{~nm}$ and the occurrence of IR bands at 3520, 3440, 
1020 and $630 \mathrm{~cm}-1$. There is also a high content of $\mathrm{SiO} 2$ (64,65\%), indicative of the presence of quartz, which is characterized by an intense peak at $0.335 \mathrm{~nm}$.

During the thermal treatment, the verdete was heated for 2 hours at a temperature of $1200{ }^{\circ} \mathrm{C}$. In order to increase the solubility of potassium present in the rock, reactions were carried out with $\mathrm{CaO}$ in proportions of 10, 20 and 30\% by weight. The structural changes in the rock were followed by XRD and IR. The changes in the position of the characteristic bands of Si-O, in the IR spectra at around $1100 \mathrm{~cm}-1$, and the disappearance of X-ray diffraction peaks, related to glauconite, confirmed the reaction between the rock and the $\mathrm{CaO}$. The reaction with $20 \%$ of $\mathrm{CaO}$ allowed an extraction of $7.7 \%$ of the potassium present in the sample.

Keywords: Verdete, thermopotassium, glauconite, slow release fertilizer.

\section{INTRODUÇÃO}

O Brasil possui um grande potencial econômico agrícola e o sucesso de sua produção está intimamente relacionado às características química e física do solo. Isto porque o país oferece solos com baixo teor de nutrientes e elevada acidez em virtude das suas condições climáticas. Assim, o emprego de uma quantidade elevada de fertilizantes, para compensar a falta de nutrientes no solo, engloba cerca de $40 \%$ dos custos variáveis de produção de alimentos. Portanto, a pesquisa para obtenção de fertilizantes alternativos é motivo de preocupação constante, em virtude do aumento da demanda por alimentos. A utilização de rochas como fonte de nutrientes para agricultura pode contribuir para reduzir o consumo de fertilizantes industriais, que demandam grande quantidade de energia para sua fabricação [1-3].

O potássio é um macronutriente essencial para o crescimento das plantas, atuando na ativação de vários sistemas enzimáticos, muitos deles participantes dos processos de fotossíntese e respiração; na síntese de proteínas, carboidratos e trifosfato de adenosina (ATP); na regulação osmótica; na manutenção de água nas plantas por meio da abertura e fechamento dos estômatos e na resistência da planta a incidência de pragas [4]. Esse nutriente é particularmente importante para culturas como cana-de-açúcar, batata, eucalipto e frutas [5].

Os principais minerais de potássio explorados são a silvita $(\mathrm{KCl})$ e a carnalita $\left(\mathrm{KMgCl}_{3} \cdot 6 \mathrm{H}_{2} \mathrm{O}\right)$. A silvinita é uma rocha composta por halita $(\mathrm{NaCl})$ e silvita $(\mathrm{KCl})$ [6]. Outros minerais menos explorados, mas também importantes são a langbeinita $\left(\mathrm{KMg}_{2}\left(\mathrm{SO}_{4}\right)_{3}\right)$, polihalita $\left(\mathrm{K}_{2} \mathrm{MgCa}_{2}\left(\mathrm{SO}_{4}\right)_{4} \mathrm{H}_{2} \mathrm{O}\right)$ e kainita $\left(4 \mathrm{KCl}_{4} \mathrm{MgSO}_{4} \cdot 11 \mathrm{H}_{2} \mathrm{O}\right)$. No Brasil existe apenas uma mina produtora de $\mathrm{KCl}$ (a partir de silvinita) em operação, a de Taquari Vassouras, em Sergipe. Esta unidade produziu aproximadamente 716 mil toneladas de $\mathrm{KCl}$ em 2010, o que corresponde a apenas 10\% das necessidades do país [7].

As rochas ou minerais industriais que apresentam elevados teores de potássio podem ser utilizadas como fontes alternativas para a produção de sais de potássio ou aplicação direta no solo como fertilizantes de liberação lenta. Deste modo, o desenvolvimento de um novo insumo agrícola, derivado de uma rocha existente no território nacional, beneficiaria o setor agrícola e mineral [8,9]. Dentre estas rochas o verdete se destaca por apresentar uma porcentagem de $\mathrm{K}_{2} \mathrm{O}$ que varia entre 6 e $14 \%$, sua coloração verde se deve a presença de íons $\mathrm{Fe}^{2+}$ na estrutura da glauconita, que é seu principal constituinte [10]. A glauconita é um silicato lamelar hidratado de potássio e ferro. As lamelas do mineral são compostas por 3 folhas (2 tetraédricas e 1 octaédrica). Nas folhas octaédricas há a substituição isomórfica de mais da metade dos íons $\mathrm{Al}^{3+}$ por $\mathrm{Fe}^{2+}[11,12]$. Na glauconita, o cátion interlamelar predominante é o $\mathrm{K}^{+}$, podendo haver também os íons $\mathrm{Na}^{+}$e $\mathrm{Ca}^{2+}[12]$.

Fertilizantes termopotássicos são aqueles resultantes do tratamento térmico de rochas potássicas, com ou sem adição de outros tipos de rocha. O tratamento térmico tem como objetivo a destruição da estrutura cristalina dos minerais fontes de potássio para formação de compostos nos quais este nutriente se encontre numa forma mais disponível aos vegetais. Os fertilizantes termopotássicos caracterizam-se por insolubilidade em água e solubilidade em ácido cítrico e em solução de citrato de amônio. Esses fertilizantes possuem caráter alcalino [13, 14].

Neste trabalho será utilizado como fonte de potássio o verdete de Cedro do Abaeté, município que está situado na bacia do Rio São Francisco, no estado de Minas Gerais (Brasil), a cerca de $285 \mathrm{Km}$ de Belo Horizonte [15]. Este verdete é uma rocha sedimentar que contém quartzo e minerais potássicos, ocorre na Serra da Saudade e geologicamente está localizado no Cráton do São Francisco, Grupo Bambuí. Dentre estes minerais potássicos destaca-se a glauconita como principal constituinte do verdete de Cedro do Abaeté [10]. 
Além da caracterização deste verdete, também será realizado um estudo da reação deste com diferentes quantidades de $\mathrm{CaO}$, visando aumentar a solubilidade do potássio presente nessa rocha.

\section{MATERIAIS E MÉTODOS}

\subsection{Preparo do material}

Para o desenvolvimento deste estudo foram coletadas amostras de verdete no município de Cedro do Abaeté. As amostras foram misturadas e homogeneizadas, seguindo-se o procedimento padrão desenvolvido no Centro de Tecnologia Mineral - CETEM/MCT [16].

A primeira etapa deste trabalho constou da preparação da amostra. Nesta procedeu-se a cominuição do material, com auxílio de um britador de mandíbulas. O produto da britagem foi rebritado em um britador de rolos, operando em circuito fechado com uma peneira de 2,38 mm (8 malhas). Na etapa seguinte o material foi homogeneizado em pilha prismática de $10 \mathrm{~m}$ de comprimento, utilizando as facilidades da usina-piloto do CETEM. De início, procedeu-se a distribuição da amostra em pilha de homogeneização, da qual foram retiradas amostras de $20 \mathrm{~kg}$. Na etapa seguinte com amostra de $20 \mathrm{~kg}$, foi feita uma nova pilha de homogeneização para coleta de alíquotas de $1,0 \mathrm{~kg}$ que foram utilizadas neste estudo. Na Figura $1 \mathrm{um}$ diagrama com as etapas de preparação das amostras estudadas é apresentado.

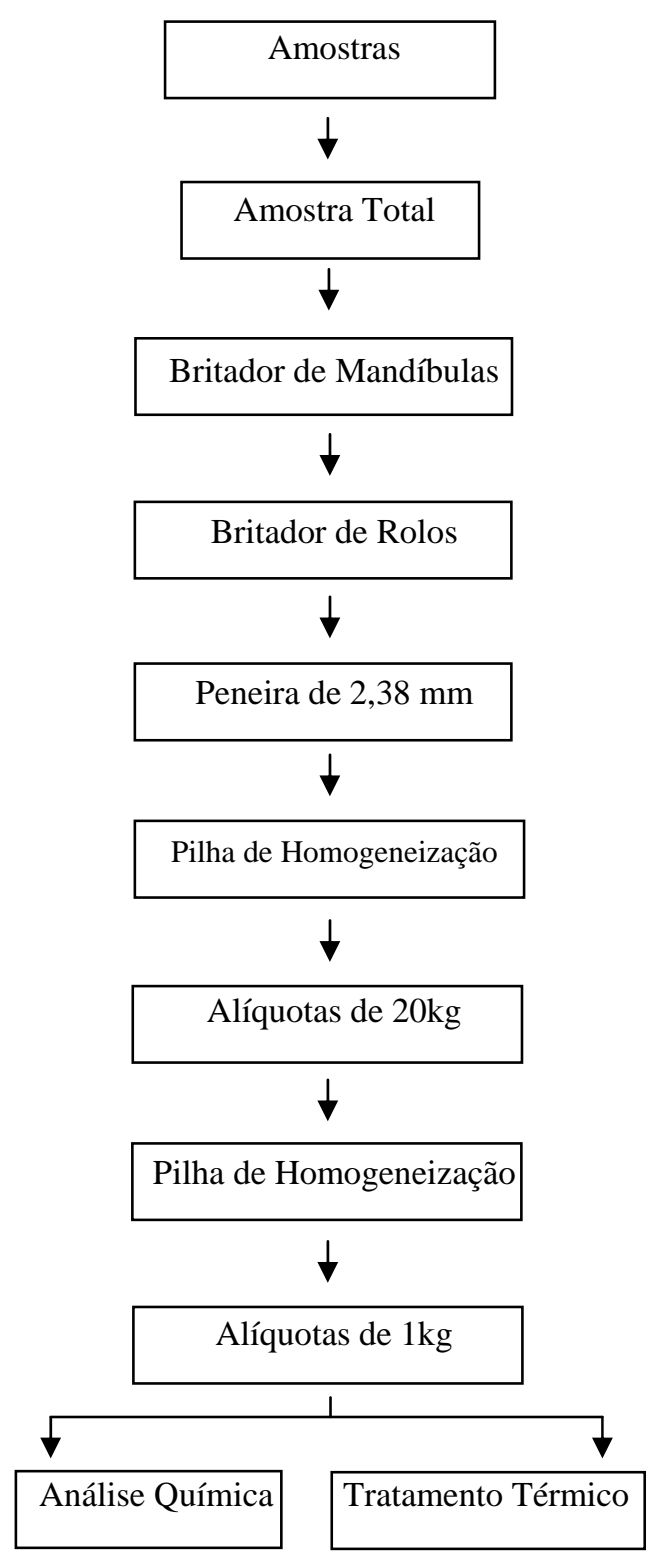

Figura 1: Fluxograma de preparo das amostras. 


\subsection{Tratamento térmico}

Nos experimentos de tratamento térmico, 10,0 gramas de material foram pesados em cadinho de porcelana. Além do verdete in natura, foram feitas também misturas de verdete com CaO a 10, 20 e 30\% em massa. Na Tabela 1 são apresentadas as proporções entre o minério e CaO.

Tabela 1: Proporções entre o verdete de Cedro do Abaeté e $\mathrm{CaO}$ utilizados nos experimentos de tratamento térmico

\begin{tabular}{c|c|c}
\hline AMOSTRA & VERDETE (g) & CaO (g) \\
\hline VDT-14 & 10,0 & 0,0 \\
\hline VDT-11 & 9,0 & 1,0 \\
\hline VDT-12 & 8,0 & 2,0 \\
\hline VDT-13 & 7,0 & 3,0 \\
\hline
\end{tabular}

As misturas apresentadas na Tabela 1 foram levadas ao forno por 2 horas a uma temperatura constante de $1200{ }^{\circ} \mathrm{C}$. Logo após este período, o material foi submetido a um choque térmico em água a temperatura ambiente. O material vítreo obtido foi retirado do cadinho, macerado com o auxílio de gral e pistilo, peneirado abaixo de 0,149 mm e enviado para análise química.

\subsection{Extração em meio ácido}

Depois de retirado do cadinho de porcelana, 5 gramas do material calcinado foram adicionados a um erlenmeyer que continha $50 \mathrm{~mL}$ de solução de ácido acético $1 \mathrm{~mol} / \mathrm{L}$. O erlenmeyer foi levado a uma mesa agitadora onde permaneceu por 4 horas. Depois de transcorrido o tempo de agitação, a solução foi filtrada e enviada para análise química por absorção atômica para a determinação do teor de $\mathrm{K}_{2} \mathrm{O}$ extraído.

\subsection{Ativação mecanoquímica}

Visando aumentar a reatividade da rocha esta foi dispersa em água, formando uma polpa com $50 \%(\mathrm{~m} / \mathrm{m})$ da rocha, a seguir a polpa sofreu uma ativação em moinho de barras por 1 e 3 horas. O material obtido foi seco em estufa e aquecido a $1200{ }^{\circ} \mathrm{C}$ por 2 horas. Posteriormente, a mistura da rocha com $30 \%$ de $\mathrm{CaO}$ sofreu a mesma ativação mecanoquímica e tratamento térmico.

\subsection{Caracterização}

A caracterização química e mineralógica dos materiais foi feita por difração de raios X (DRX), espectroscopia no infravermelho (IV), fluorescência de raios X (FRX) e microscopia eletrônica de varredura (MEV).

Difração de Raios X: Os difratogramas foram obtidos pelo método do pó, foram coletados em um equipamento Bruker-D4 Endeavor, nas seguintes condições de operação: radiação CoK $\alpha(40 \mathrm{kV} / 40 \mathrm{~mA})$ $\lambda=0,178897 \mathrm{~nm}$; velocidade do goniômetro de $0,02^{\circ}(2 \theta)$ por passo com tempo de contagem de 0,5 segundos por passo e coletados de 4 a $80^{\circ}(2 \theta)$, com detector sensível à posição LynxEye. As interpretações qualitativas de espectro foram efetuadas por comparação com padrões contidos no banco de dados PDF02 em software Bruker DiffracPlus.

Fluorescência de Raios X: Nesta análise, a amostra foi preparada por prensagem do material sob pressão de 20 toneladas. A pastilha obtida foi analisada em espectrômetro de fluorescência de raios $\mathrm{X}$ BRUKER-AXS modelo S4- Explorer, equipado com tubo de Rh. Para obtenção da análise química semiquantitativa, o espectro gerado a partir da amostra foi avaliado pelo software Spectra plus v.1.6 no modo standardless method, ou seja, sem curva de calibração específica.

Espectroscopia no Infravermelho: a análise por espectroscopia no infravermelho foi realizada em equipamento Bomem - Hartmann \& Braun - com registros de 4000 a $400 \mathrm{~cm}^{-1}$ e medições a cada $4 \mathrm{~cm}^{-1}$. 
Microscopia Eletrônica de Varredura: a morfologia das amostras foi determinada em microscópio eletrônico de varredura LEICA modelo F440, em modo de alto vácuo. As partículas previamente dispersas foram recobertas com prata para torná-las condutoras.

\section{RESULTADOS E DISCUSSÃO}

\subsection{Caracterização do Verdete}

$\mathrm{O}$ difratograma de raios $\mathrm{X}$ da amostra de verdete de Cedro do Abaeté é apresentado na Figura 2. Pela análise do mesmo pode-se determinar que o minério é contituído por glauconita $\left(\mathrm{K}_{2}(\mathrm{MgFe})_{2} \mathrm{Al}_{6}\left(\mathrm{Si}_{4} \mathrm{O}_{10}\right)_{3}(\mathrm{OH})_{12}\right)$, quartzo $\left(\mathrm{SiO}_{2}\right)$, clorita serpentina $\left((\mathrm{MgAl})_{6}(\mathrm{SiAl})_{4} \mathrm{O}_{10}(\mathrm{OH})_{8}\right)$ e ilita $\left(\mathrm{KAl}_{2}\left[(\mathrm{SiAl})_{4} \mathrm{O}_{10}\right][\mathrm{OH}]_{2}\right)$. Sabe-se que a glauconita é um mineral micáceo semelhante a ilita e devido a esta similaridade há uma certa dificuldade em discriminar uma ilita de uma glauconita em um difratograma de raios X [17]. Entretanto, com base nas reflexões observadas em 1,00; 0,45; 0,34; 0,24 e $0,15 \mathrm{~nm}$ pode-se confirmar a presença do mineral glauconita [12]. Estes resultados foram validados com base no banco de dados PDF02 (Internacional Center for Diffraction Data - ICDD).

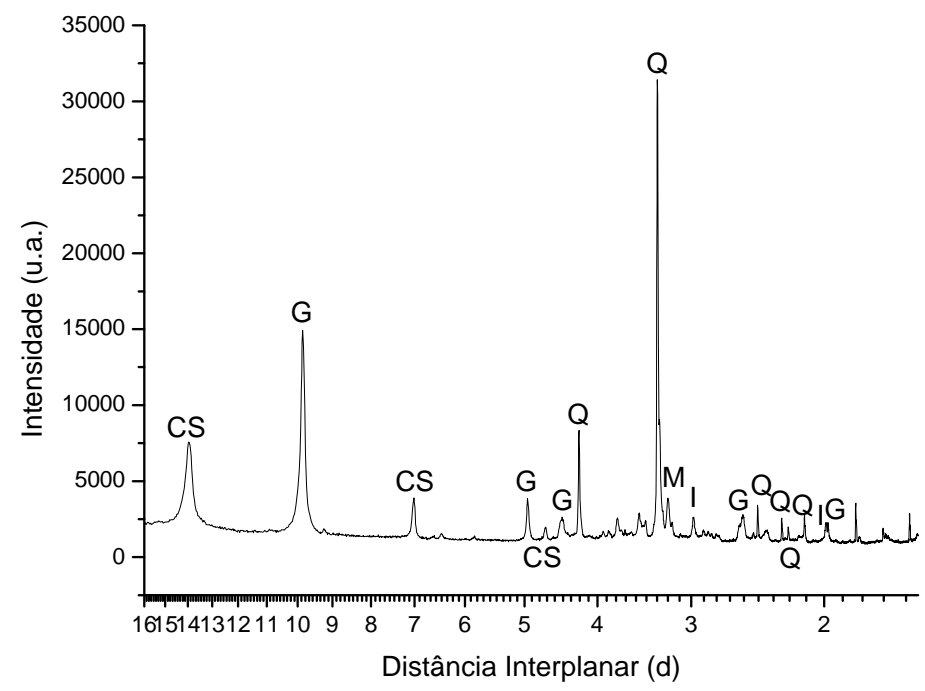

Figura 2: Difratograma de Raios X para a Amostra de Verdete de Cedro do Abaeté.

Pela análise dos resultados obtidos por fluorescência de raios X (Tabela 2) pode-se observar que o verdete de Cedro do Abaeté é composto basicamente por $\mathrm{SiO}_{2}$ (64,65\%), $\mathrm{Al}_{2} \mathrm{O}_{3}$ (13,52\%) e $\mathrm{K}_{2} \mathrm{O}$ (6,95\%). O alto teor de sílica se refere principalmente à ocorrência do mineral quartzo, assim como, a ocorrência de minerais aluminossilicatos, identificados nos difratogramas de raios $\mathrm{X}$, ou seja, minerais que apresentam em sua composição principalmente alumínio e silício, estes últimos também explicam o alto teor de alumínio. O potássio se apresenta de forma bastante expressiva na composição química do verdete de Cedro do Abaeté, este teor (6,95\%) pode ser atribuído a ocorrência do mineral glauconita que é o principal mineral constituinte da amostra. Além do potássio, macro nutriente essencial para o desenvolvimento das plantas, observa-se que a amostra em estudo apresenta outros nutrientes igualmente importantes para o crescimento das plantas, tais como, $\mathrm{MgO}(1,98 \%), \mathrm{CaO}(0,14 \%)$ e $\mathrm{P}_{2} \mathrm{O}_{5}(0,134 \%)$.

O espectro de infravermelho obtido para a amostra de verdete de Cedro do Abaeté é apresentado na Figura 3. Podem-se observar bandas típicas da glauconita, relativas ao estiramento da ligação OH, em 3614, 3557, 3533 e $3417 \mathrm{~cm}^{-1}$ [18]. A estrutura do silicato é caracterizada pela presença de bandas ao redor de 1013 $\mathrm{cm}^{-1}$ que são atribuídas aos modos de vibração de estiramento das ligações Si-O-Si. Observam-se bandas dos modos de deformação referentes às ligações Si-O-Fe e Si-O em $518 \mathrm{~cm}^{-1}$ e $468 \mathrm{~cm}^{-1}$, respectivamente. 
Tabela 2: Composição química da amostra de verdete de Cedro do Abaeté.

\begin{tabular}{c|c}
\hline ÓxiDO & $\begin{array}{c}\text { TEOR (\%) } \\
\text { EM MASSA }\end{array}$ \\
\hline $\mathrm{SiO}_{2}$ & 64,65 \\
\hline $\mathrm{Al}_{2} \mathrm{O}_{3}$ & 13,52 \\
\hline $\mathrm{Fe}_{2} \mathrm{O}_{3}$ & 5,71 \\
\hline $\mathrm{CaO}$ & 0,14 \\
\hline $\mathrm{MgO}$ & 1,98 \\
\hline $\mathrm{Na}_{2} \mathrm{O}$ & 0,24 \\
\hline $\mathrm{K}_{2} \mathrm{O}$ & 6,95 \\
\hline $\mathrm{Cr}_{2} \mathrm{O}_{3}$ & 0,02 \\
\hline $\mathrm{TiO}_{2}$ & 0,74 \\
\hline $\mathrm{MnO}$ & 0,11 \\
\hline $\mathrm{P}_{2} \mathrm{O}_{5}$ & 0,134 \\
\hline $\mathrm{SrO}$ & 0,01 \\
\hline $\mathrm{BaO}$ & 0,07 \\
\hline $\mathrm{Perda} \mathrm{ao} \mathrm{Fogo}$ & 4,39 \\
\hline
\end{tabular}

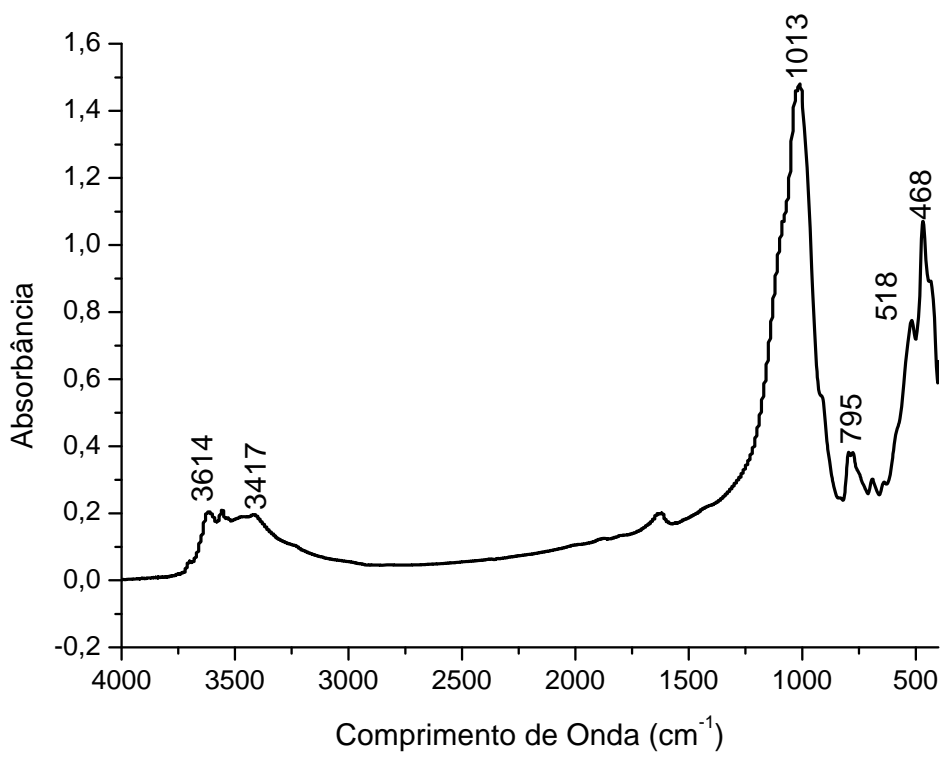

Figura 3: Espectro obtido no infravermenlho para a amostra de verdete de Cedro do Abaeté.

A morfologia da amostra estudada foi determinada por microscopia eletrônica de varredura. Pela análise das imagens obtidas (Figura 4) fica claro que o verdete apresenta-se como um material particulado. 


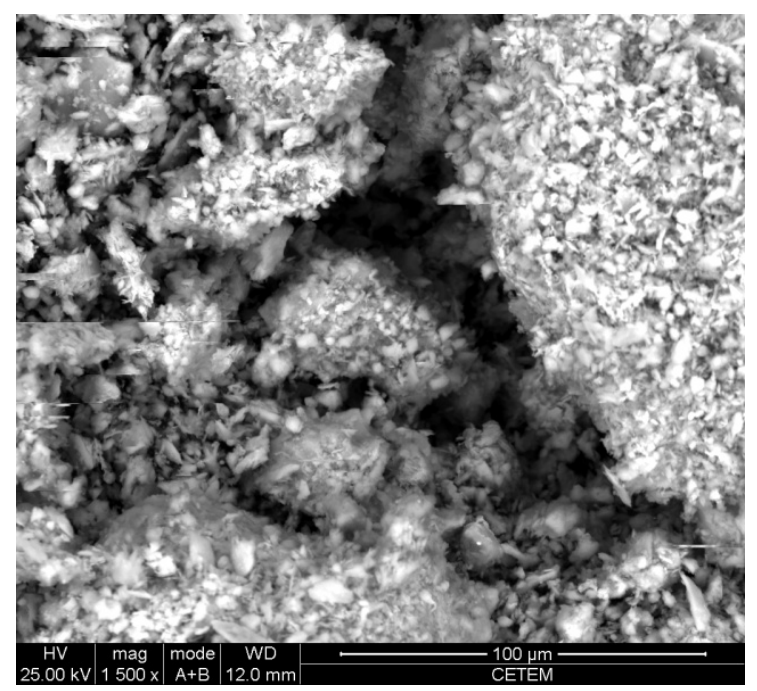

Figura 4: Microscopia Eletrônica de Varredura do Verdete de Cedro do Abaeté.

\subsection{Tratamento térmico}

Os difratogramas de raios $\mathrm{X}$ das amostras calcinadas a $1200{ }^{\circ} \mathrm{C}$ são apresentados na Figura 5 . Em todas as amostras calcinadas observa-se o desaparecimento dos picos da glauconita $\left(\mathrm{K}_{2}(\mathrm{MgFe})_{2} \mathrm{Al}_{6}\left(\mathrm{Si}_{4} \mathrm{O}_{10}\right)_{3}(\mathrm{OH})_{12}\right)$ e a presença de um halo (abaulamento da linha base) nos difratogramas, em aproximadamente $\mathrm{d}=0,30-$ $0,40 \mathrm{~nm}$, indicando a formação de material amorfo. A amostra VDT-14, corresponde ao material calcinado sem a adição de $\mathrm{CaO}$. Nessa amostra, observa-se a presença dos picos referêntes ao quartzo e o surgimento de novos picos, atribuídos à fase espinélo $\left(\mathrm{MgAl}_{2} \mathrm{O}_{4}\right)$. Na amostra VDT-11, calcinada com $10 \%$ em massa de $\mathrm{CaO}$, o picos observados são basicamente os mesmos da amostra VDT-14, sendo que, o halo referente ao material amorfo apresenta uma maior intensidade relativa. No difratograma da amostra VDT-12, calcinada com $20 \%$ em massa de $\mathrm{CaO}$, notou-se o surgimento das fases espinélo, anortita $\left(\mathrm{CaAl}_{2} \mathrm{Si}_{2} \mathrm{O}_{8}\right)$ e silicato de cálcio hidratado $\left(\mathrm{Ca}_{2} \mathrm{SiO}_{4} .50 \mathrm{H}_{2} \mathrm{O}\right)$, sendo que há uma diminuição significativa na intensidade dos picos de difração do quartzo. Na amostra VDT-13, calcinada com 30\% em massa de $\mathrm{CaO}$, foi identificada a presença de silicato de potássio e cálcio $\left(\mathrm{K}_{4} \mathrm{CaSi}_{3} \mathrm{O}_{9}\right)$, como fase principal, além de outras fases cristalinas tais como espinélo, silicato hidratado de cálcio $\left(\mathrm{Ca}_{2} \mathrm{SiO}_{4} .50 \mathrm{H}_{2} \mathrm{O}\right)$ e anortita $\left(\mathrm{CaAl}_{2} \mathrm{Si}_{2} \mathrm{O}_{8}\right)$. Nota-se, também, que para esta amostra quase todo o quartzo foi consumido pela reação com $\mathrm{CaO}$.

Os espectros de infravermelho obtidos para as amostras de verdete de Cedro do Abaeté após a calcinação são apresentados na Figura 6. Para as amostras VDT-14 e VDT-11 observa-se uma banda em aproximadamente $780 \mathrm{~cm}^{-1}$ que pode ser atribuída ao modo de deformação da ligação Si-O, devido à presença de sílica amorfa no material [19]. Para materiais amorfos com alto conteúdo de sílica, normalmente pode-se observar em espectros no infravermelho o aparecimento de bandas referentes à vibração de estiramento das ligações do grupamento $\mathrm{SiO}_{4}$ em aproximadamente $1100 \mathrm{~cm}^{-1}[19,20]$. Na amostra VDT-14, calcinada sem a adição de $\mathrm{CaO}$, pode-se notar uma banda com essas características em $1071 \mathrm{~cm}^{-1}$. Quando uma espécie modificadora de rede como, por exemplo, $\mathrm{CaO}$ é introduzido na rede do material amorfo essa banda é progressivamente levada para comprimentos de onda mais baixos como é observado nas amostras VDT-11, VDT-12 e VDT-13. À medida que se aumenta o teor de CaO observa-se a diminuição do comprimento de onda dessa banda, devido a incorporação dos íons cálcio na estrutura vítrea do material [19, 20]. Além disso, no caso da amostra VDT-13, observam-se também desdobramentos nas bandas do espectro IV, com o aparecimento de uma nova banda em $941 \mathrm{~cm}^{-1}$, esta observação está de acordo com o surgimento de novas fases cristalinas, evidenciadas no DRX dessa amostra (Figura 5). 


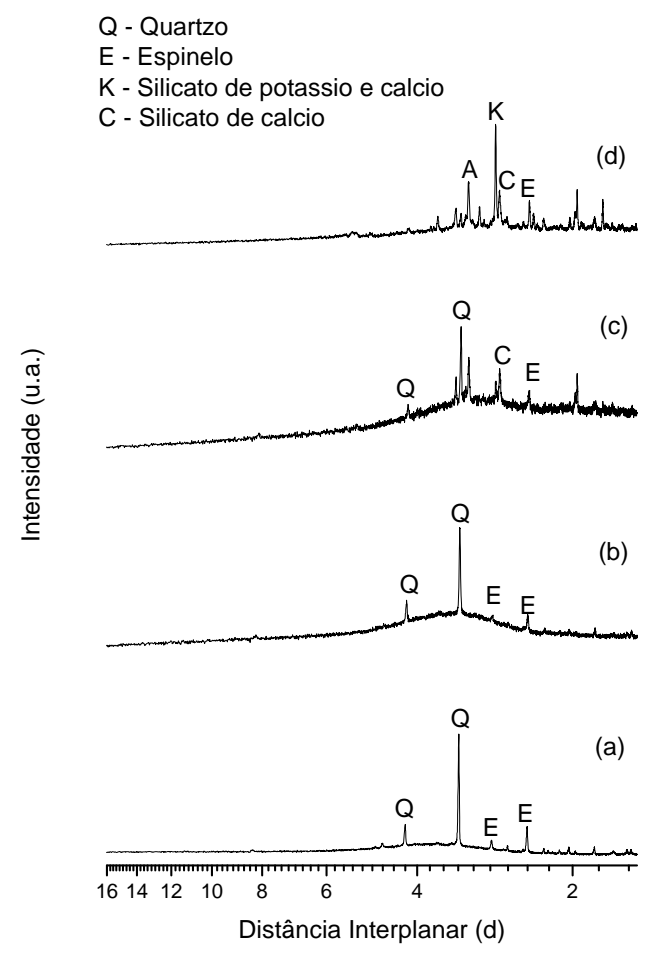

Figura 5: Difratogramas de Raios X para as Amostras (a) VDT-14, Calcinada sem Adição de CaO, (b) VDT11, Calcinada com Adição de 10\% de CaO, (c) VDT-12, Calcinada com Adição de $20 \%$ de CaO, (d) VDT13, Calcinada com Adição de 30\% de $\mathrm{CaO}$.

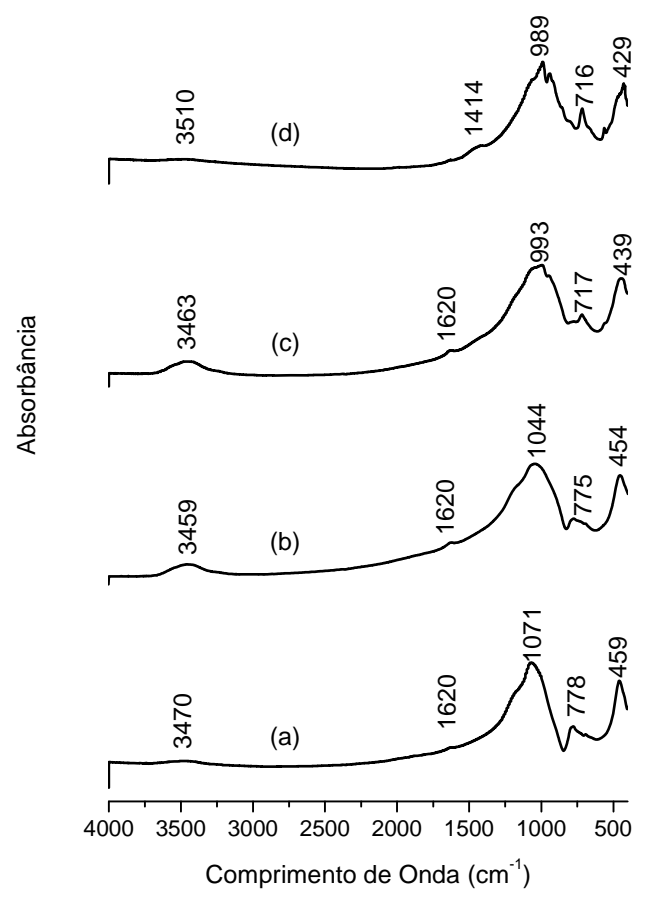

Figura 6: Espectroscopia no Infravermelho para as amostras (a) VDT-14, Calcinada sem Adição de CaO, (b) VDT-11, Calcinada com Adição de 10\% de CaO, (c) VDT-12, Calcinada com Adição de 20\% de CaO, (d) VDT-13, Calcinada com Adição de 30\% de CaO. 


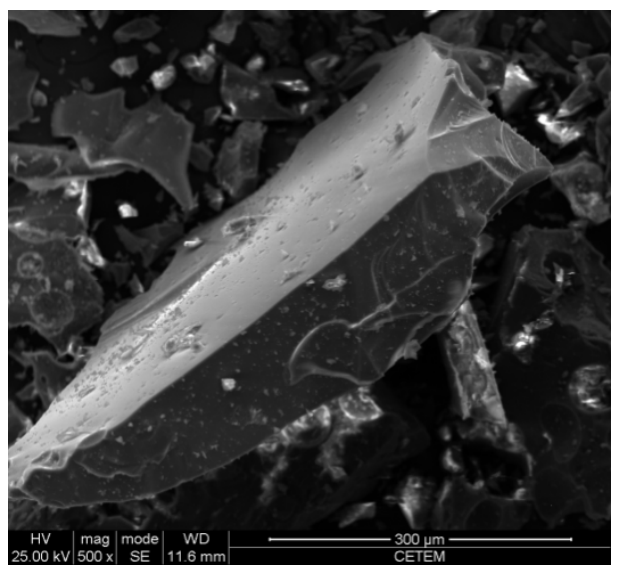

(a)

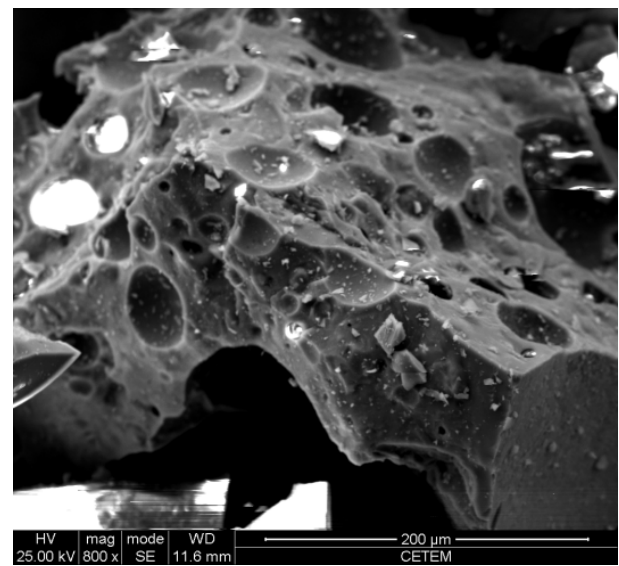

(b)

Figura 7: Microscopia Eletrônica de Varredura das amostras (a) VDT-11 e (b) VDT-12.

Na Figura 7 observam-se as imagens obtidas por microscopia eletrônica de varredura das amostras VDT-11 e VDT-12. As imagens mostram uma morfologia típica de material vítreo, muito diferente da morfologia de material particulado do verdete de partida (Figura 4).

\subsection{Extração em meio ácido}

Com o objetivo de quantificar a taxa de liberação de potássio nos minerais fontes deste nutriente na amostra, experimentos de extração em meio ácido utilizando-se ácido cítrico foram desenvolvidos. Trabalhos apresentados na literatura reportam a ação destes ácidos na dinâmica de liberação de potássio de minerais, solos e suas frações granulométricas [15, 21, 22]. Os ácidos orgânicos de baixo peso molecular, como o ácido cítrico e o oxálico, são utilizados como extratores padrão em estudos de cinética de liberação de potássio em solos uma vez que podem facilitar a intemperização de minerais pela formação de compostos nos quais o potássio encontra-se mais disponível [21]. A Tabela 3 apresenta os resultados obtidos para os ensaios de extração de potássio no material em ácido cítrico.

Tabela 3: Teor de potássio extraído do verdete de Cedro do Abaeté antes e depois do tratamento térmico e reação com $\mathrm{CaO}$

\begin{tabular}{c|c|c|c}
\hline AMOSTRA & $\begin{array}{c}\text { K}_{2} \text { O TOTAL DA } \\
\text { AMOSTRA (mg) }\end{array}$ & $\begin{array}{c}\mathbf{K}_{\mathbf{2}} \text { O EXTRAídO } \\
\text { (mg/L) }\end{array}$ & $\begin{array}{c}\text { K }_{\mathbf{2}} \text { O EXTRAíDO EM } \\
\text { RELAÇÃO AO TEOR } \\
\text { TOTAL DA AMOSTRA (\%) }\end{array}$ \\
\hline Verdete in natura & 6950 & 28,8 & 0,40 \\
\hline VDT-14 & 6950 & 4,1 & 0,06 \\
\hline VDT-11 & 6255 & 396,0 & 6,33 \\
\hline VDT-12 & 5560 & 426,5 & 7,67 \\
\hline VDT-13 & 4865 & 243,0 & 5,00 \\
\hline
\end{tabular}

Pela análise da Tabela 3 pode-se notar que para o material de partida (verdete in natura) após 4 horas de extração em ácido cítrico $1 \mathrm{~mol} / \mathrm{L}$, o percentual obtido foi de $0,4 \%$ de $\mathrm{K}_{2} \mathrm{O}$ extraído. Esse teor baixo é devido à alta cristalinidade do minério que é evidenciado nos dados de difração de raios X (Figura 2). Para o verdete calcinado sem adição de $\mathrm{CaO}$ o percentual é ainda mais baixo (0,06\%) apesar da cristalinidade do material ter diminuído, uma vez que, a fase amorfa formada, rica em sílica, é de baixa solubilidade e portanto os íons potássio ficam ainda mais retidos na estrutura do material.

No entanto, com o acréscimo de $\mathrm{CaO}$, os teores de extração de potássio aumentam consideravelmente. Para os materiais calcinados com 10, 20 e 30\% de $\mathrm{CaO}$ os percentuais de extração obtidos foram de 6,4; 7,7 e 4,2\%, respectivamente. Esses resultados vêm corroborar as informações apresentadas até o momento, uma vez que, pelos dados de caracterização estrutural desses materiais notou-se que à medida que se aumenta o 
teor de CaO, conhecido modificador de rede vítrea [19], aumenta-se também a quantidade de íons cálcio na estrutura vítrea do material, ou seja, as ligações Si-O-Si são quebradas pela introdução de íons $\mathrm{Ca}^{2+}$ na estrutura vítrea, tornando-a mais solúvel e aumentando portanto a disponibilidade dos íons potássio.

Deve-se destacar que, dentre os materiais com cálcio, o que possui maior teor de $\mathrm{CaO}$ foi o que apresentou menor percentual de extração. Entretanto, os resultados da caracterização estrutural do material VDT-13 (Figuras 5 e 6), indicam que quando se adicionou ao verdete $30 \%$ de $\mathrm{CaO}$ os íons potássio migraram da rede vítrea formando fases cristalinas, tais como, o silicato de cálcio e potássio, diminuindo assim a solubilidade deste íon.

\subsection{Ativação mecanoquímica}

Visando otimizar a reação entre o verdete e o $\mathrm{CaO}$ foram realizados alguns experimentos preliminares com ativação mecanoquímica, seguindo a abordagem recentemente desenvolvida em nosso laboratório [23, 24]. Em mecanoquímica do estado sólido, reações químicas ocorrem devido à deformação e fratura desses sólidos quando são ativados por efeito de uma força mecânica, isto é, a moagem. A ativação mecanoquímica de sólidos envolve o aumento da energia de superfície, da área superficial e diminuição da energia de coerência dos sólidos. Estas reações podem ocorrer durante ou após a moagem e promovem uma agregação espontânea, adsorção ou recristalização do sistema ativado.

Pelos resultados de DRX apresentados na Figura 8, é possível notar que a ativação mecanoquímica apresentou alta eficiência no que se refere à incorporação do cálcio na estrutura vítrea do material. O deslocamento do pico em aproximadamente $\mathrm{d}=0,43 \mathrm{~nm}$, que é característico para sílica amorfa, para valores menores de d, após a reação do verdete com $\mathrm{CaO}$, indica a entrada dos íons $\mathrm{Ca}^{2+}$ na rede vítrea do material.

Esses resultados são corroborados pelos resultados de espectroscopia no infravermelho, uma vez que uma espécie modificadora de rede foi introduzida na rede do material amorfo.A banda característica para sílica amorfa foi progressivamente levada para comprimentos de onda mais baixos como é observado na Figura 9. Já que não houve variação no teor de $\mathrm{CaO}$ adicionado ao material de partida a diminuição do comprimento de onda da banda característica foi praticamente a mesma nos diferentes tempos de moagem do material.

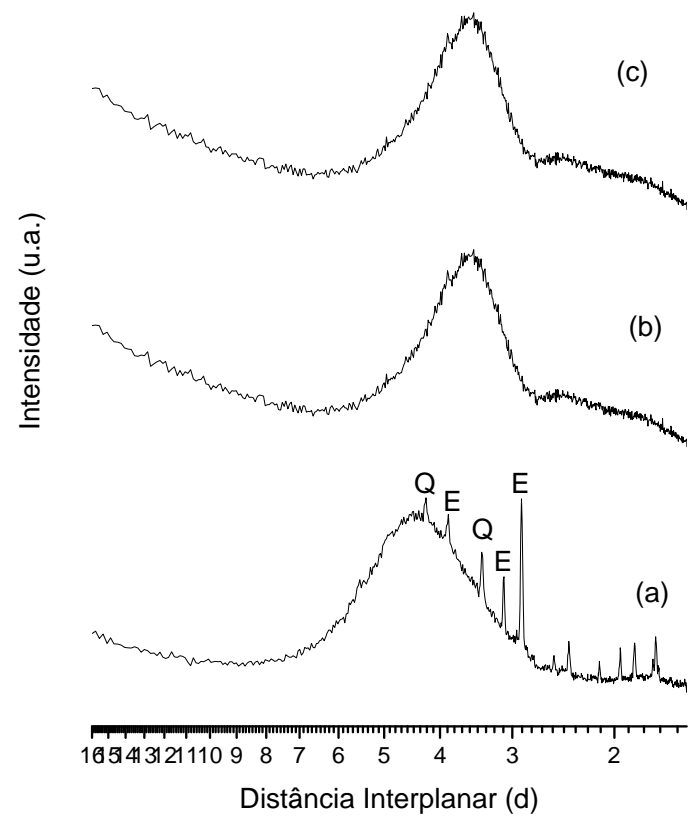

Figura 8: Difratogramas de Raios X para a Amostra Calcinada (a) Ativada Mecanoquimicamente sem Adição de $\mathrm{CaO}$ por 1 hora (b) Ativada Mecanoquimicamente Com a Adição de 30\% de CaO por 1 hora, (c) Ativada Mecanoquimicamente Com a Adição de $30 \%$ de $\mathrm{CaO}$ por 3 horas. 


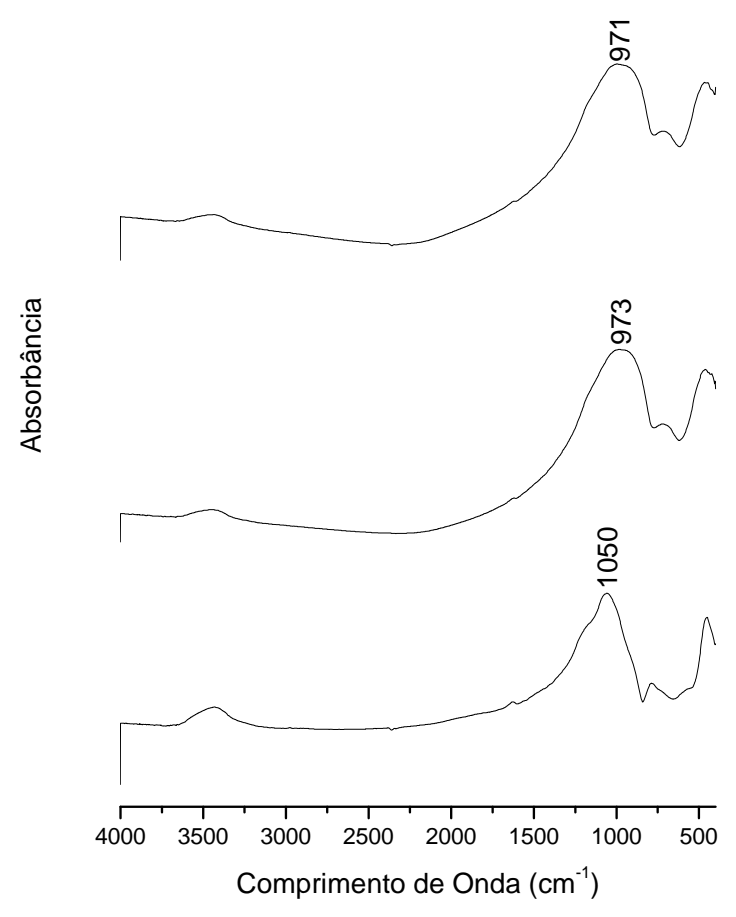

Figura 9: Espectroscopia no Infravermelho para as Amostras Calcinadas: (a) Ativada mecanoquimicamente com a adição de 30\% de $\mathrm{CaO}$ por 1 hora, (b) Ativada Mecanoquimicamente com a adição de $30 \%$ de $\mathrm{CaO}$ por 3 horas, (c) ativada mecanoquimicamente sem adição de $\mathrm{CaO}$ por 1 hora.

\section{CONCLUSÕES}

O verdete de Cedro do Abaeté in natura é uma rocha composta basicamente por quartzo e glauconita e apresenta um teor de $\mathrm{K}_{2} \mathrm{O}$ de aproximadamente $7 \%$. No entanto, somente uma parcela deste nutriente encontra-se na forma solúvel. Para o verdete in natura somente $0,4 \%$ da quantidade total de $\mathrm{K}_{2} \mathrm{O}$ ficou disponível após 4 horas de extração em solução de ácido cítrico 1,0 mol/L. Quando calcinado sem adição de $\mathrm{CaO}$ este valor diminui para $0,06 \%$ devido a formação de uma fase amorfa rica em sílica e de baixa solubilidade, que provavelmente contém a maior parte do potássio. Por outro lado, a reação com CaO à 1200 ${ }^{\circ} \mathrm{C}$, nas quantidades de 10, 20 e 30\%, permite que, respectivamente, 6,4; 7,7 e 4,2\%, da quantidade total de $\mathrm{K}_{2} \mathrm{O}$ presente na amostra se solubilize em solução de ácido cítrico 1,0 mol/L.

Os resultados preliminares, da estrutura dos materiais formados com a ativação mecanoquímica, indicam que é possível evitar a formação de fases cristalinas, o que em princípio deve aumentar a solubilidade dos íons potássio.

Dessa forma, pode-se concluir que o verdete de Cedro do Abaeté apresenta potencial para ser utilizado como fertilizante alternativo em culturas que demandem potássio em longo prazo, como por exemplo, culturas perenes. No entanto, para uma aplicação mais segura deste material serão realizados testes agronômicos em casa de vegetação para o monitoramento do crescimento das espécies vegetais e assimilação do $\mathrm{K}_{2} \mathrm{O}$ pelas mesmas.

\section{AGRADECIMENTOS}

Os autores agradecem a CAPES e ao CNPq pelo suporte financeiro, ao Instituto de Química da Universidade Federal do Rio de Janeiro e ao Centro de Tecnologia Mineral/MCT pelo suporte laboratorial.

\section{BIBLIOGRAFIA}

[1] LAPIDO LOUREIRO, F.E., NASCIMENTO, M. "Importância e função dos fertilizantes numa agricultura sustentável e competitiva”, In: Lapido Loureiro, F.E., Melamed, R., Figueiredo Neto, J. (eds), 
Fertilizantes: Agroindústria e Sustentabilidade, 1 ed., capítulo 2, Rio de Janeiro, Centro de Tecnologia Mineral, Ministério da Ciência e Tecnologia, 2009.

[2] FYFE,W.S., LEONARDOS, O.H., THEODORO, S.H., "Sustainable farming with native rocks: the transition without revolution”, Anais da Academia Brasileira de Ciências, v. 78, n. 4, pp. 715-720, 2006.

[3] VAN STRAATEN, P., "Farming with rocks and minerals: challenges and opportunities", Anais da Academia Brasileira de Ciências, v. 78, n. 4, pp. 731-747, 2006.

[4] ERNANI, P.R., ALMEIDA, J.A., SANTOS, F.C., "Potássio”, In: Novais, R.F., Barros, N.F., Fontes, L.R.F., et al. (eds), Fertilidade do Solo, 1 ed., capítulo 9, Viçosa, Minas Gerais, Sociedade Brasileira de Ciência do Solo, 2007.

[5] VAN STRAATEN, P. "Potassium”, Agrogeology: The Use of Rocks for Crops, 1 ed., chapter 5, Guelph, Canada, Enviroquest Ltd., 2007.

[6] NASCIMENTO, M., MONTE, M.B.M., LAPIDO LOUREIRO, F.E., “Agrominerais - Potássio”, In: da Luz, A.B., Lins, F.A.F. (eds), Rochas e Minerais Industriais : Usos e Especificações, 2 ed., capítulo 8, Rio de Janeiro, Centro de Tecnologia Mineral, Ministério da Ciência e Tecnologia, 2008.

[7] OLIVEIRA, L.A.M., 2011, DNPM - Departamento Nacional de Produção Mineral, Sumário Mineral, 2011, disponível em:

https://sistemas.dnpm.gov.br/publicacao/mostra_imagem.asp?IDBancoArquivoArquivo=6388. Acessado no dia 05/12/2012.

[8] RESENDE, A.V.; MARTINS, E.S.; OLIVEIRA, C.G., et al., "Suprimento de potássio e pesquisa de uso de rochas 'in natura' na agricultura brasileira”, Revista Espaço e Geografia, v. 9, pp. 19-42, 2006.

[9] RIBEIRO, L.S., SANTOS, A. R., SOUZA, L.F.S. et al., "Rochas silicáticas portadoras de potássio como fontes do nutriente para as plantas solo", Revista Brasileira de Ciência do Solo, v. 34, pp. 891-897, 2010.

[10] PIZA, P.A.T., FRANÇA, S.C.A., BERTOLLINO, L.C., et al., "Verdete do Cedro de Abaeté (MG) como fonte alternativa para potássio”, In: XVII Jornada Interna de Iniciação Científica do CETEM , 1286-32, Rio de Janeiro, Rio de Janeiro, Brasil, 192-198, Julho 2009.

[11] KOSTER, H.M., "Determination of the chemical structural formula of 2:1 layer silicates based on the measurement of the interlayer charge and cation exchange capacities", Clay Minerals, v. 12, pp. 45-54, 1977.

[12] SRASRA, E., TRABELSI-AYEDI, M. “Textural properties of acid activated glauconite”, Applied Clay Science, v. 17, pp. 71-84, 2000.

[13] SOUZA, E.C.A., YASUDA, M. "Uso Agronômico do Termofosfato no Brasil”, In: Lapido Loureiro, F.E., Melamed, R., Figueiredo Neto, J. (eds), Fertilizantes: Agroindústria e Sustentabilidade, 1 ed., capítulo 21, Rio de Janeiro, Centro de Tecnologia Mineral,Ministério da Ciência e Tecnologia 2009.

[14] ORIOLI JUNIOR, V., COUTINHO, E.L.M. "Effectiviness of Fused Magnesium Potassium Phosphate for Marandu Grass”, Revista Brasileira de Ciência do Solo, v. 33 pp. 1855-1862, 2009.

[15] VALLARELI. J.V. et al., “Ardósias Verdete de Cedro do Abaeté na Produção de Termofosfato Potássico Fundido e sua Eficiência Agronônica”, Anais da Academia Brasileira de Ciências, v. 31, pp. 363375, 1993.

[16] OLIVEIRA, M.L.M. e AQUINO, J.A. “Amostragem”, In: Sampaio, J.A., França, S.C., Braga, P.F.A. (eds.), Tratamento de Minérios Práticas Laboratoriais, 1 ed., capítulo 1, Rio de Janeiro, Centro de Tecnologia Mineral, Ministério da Ciência e Tecnologia, 2007.

[17] GAMERO, R.M.P., TORRADO, P.V., FERREIRA, T.O. "Mineralogia e físico química dos solos de mangue do rio Iriri no canal de Bertioga”, Revista Brasileira de Ciência do Solo, v. 28, pp. 233-243, 2004.

[18] OSPITALI, F., BERSANI, D., Di LEONARDO, G. e LOTTICI, P.P. “'Green earths': vibrational and elemental characterization of glauconites, celadonites in historical pigments”, Journal of Raman Spectroscopy, v. 39, pp. 1066-1073, 2008.

[19] CHRISSANTHOPOULOS, A., BOUROPOULOS, N., YANNOPOULOS, S.N. "Vibrational spectroscopic and computational studies of sol-gel derived $\mathrm{CaO}-\mathrm{MgO}-\mathrm{SiO} 2$ binary and ternary bioactive glasses”, Vibrational Spectroscopy, v. 48, pp. 118-125, 2008.

[20] BRANDA, F. et al. " $\mathrm{T}_{\mathrm{g}}$ and FTIR of (2.5 - x)CaO.x $/ 3 \mathrm{M}_{2} \mathrm{O}_{3} 2 \mathrm{SiO}_{2}(\mathrm{M}=\mathrm{Y}, \mathrm{La}, \mathrm{In}, \mathrm{Al}, \mathrm{Ga})$ glasses", Journal of Non Crystalline Solids, v. 246, pp. 27-33, 1999. 
[21] SILVA, A.A.S., Caracterização de Flogopitito da Bahia para Uso Como Fertilizante Alternativo de Potássio, Dissertação de M.Sc., IQ/UFRJ, Rio de Janeiro, RJ, Brasil, 2009.

[22] CASTILHOS, R.M.V., MEURER, E.J. “Cinética de liberação de potássio em planossolo do estado do Rio Grande do Sul”, Ciência Rural, v. 31, pp. 979-983, 2001.

[23] AZEVEDO, C.A., GARRIDO, F.M.S., MEDEIROS, M.E., “The effect of mechanochemical activation on the reactivity in the $\mathrm{MgO}-\mathrm{Al}_{2} \mathrm{O}_{3}-\mathrm{SiO}_{2}$ system”, Journal of Thermal Analysis and Calorimetry, v. 83, n. 3, pp. 649-655, 2006.

[24] SILVA, F.A.N.G., MEDEIROS, M.E., SAMPAIO, J.A., et al., “Technological Characterization of Bauxite from Pará-Brazil”, Light Metals, pp. 139-144, 2009. 